\title{
Conclusions of the 6th International Wadden Sea Symposium
}

The 6th Scientific International Wadden Sea Symposium held on the island of Sylt, Federal Republic of Germany, from 1st-4th November 1988, was devoted to environmental monitoring of the Wadden Sea.

The participants of the symposium recognized with satisfaction that some of the previous recommendations have been successfully implemented.

Monitoring is defined here as studies that acquire physical, chemical and biological data suitable for making comparisons, in time and space, of environmental parameters. This is done to detect spatial trends or local deviations as well as temporal trends and rare events. The major objective is to separate the effects of human impacts from natural variability. This assessment will allow an evaluation of the present and past changes of the ecosystem of the Wadden Sea, and will provide an instrument for present and future conservation and management policies. Another major objective is assessment of the effect of measures.

The symposium wishes to point out that monitoring in itself cannot solve any problems. The protection of the environment has to be guaranteed by national and international legislation and the consequent application of the laws.

At the symposium national regulations and the organization of data acquisition were presented, design and new techniques of monitoring programmes were discussed, and conclusions were drawn from large-scale and long-term studies.

The symposium came to the following conclusions and recommendations:

1. The symposium recommends the implementation and coordination of a trilateral, interdisciplinary monitoring effort covering the entire Wadden Sea. This programme should be based on:

A network of monitoring sites with a wide areal coverage, where appropriate measurements of environmental parameters and human activities are regularly recorded:

- A quality assurance programme including standardization and intercalibration of techniques and methods;

- Selected sites in the entire Wadden Sea, where long-term ecosystem research is to be institutionalized. Processes are to be analysed, and subjected to experimentation and simulations in mathematical models in order to guide future monitoring efforts;

- The development of well-defined quality goals

- The development of a repetitive remote sensing programme with selected ground truth locations;

- A store of preserved samples for future analysis and questions; 
- A freely accessible central facility for data processing, storage and information retrieval.

In this connection the symposium recommends the establishment of a trilateral working group of experts responsible for the development of a common monitoring programme for the Wadden Sea within one year. This should be based on existing national programmes and should be followed up by an international coordination commission based on the Common Wadden Sea Secretariat. An estimation of the cost of this programme should be made and it should indicate possibilities of funding.

2. For successful monitoring it is essential to designate reference areas in every region of the Wadden Sea including all representative ecosystems. These should be completely free from exploitation and other intentional human interference, so that they can serve as controls. If possible, these reference areas should be combined with the core zones of protected areas.

3. Data on past situations may be extremely valuable to the understanding of present developments. Therefore such data should be subjected to modern data-processing techniques.

4. The trilateral monitoring effort in the Wadden Sea is of paramount importance because of its indicative value with regards to the state of the North Sea. The Wadden Sea, together with the rivers, the immediate atmosphere and adjacent parts of the North Sea, should be included in the global network of long-term ecological research and should be augmented by a joint declaration of the Wadden Sea as an international biosphere reserve. The possible role of NGO's (non-governmental nature-organizations) should be considered in this connection.

5. International monitoring programmes such as COST 647 should be continued and included in the international Wadden Sea monitoring programme.

6. The communication between scientists and politicians should be improved. The results of the monitoring programmes should be regularly presented in a language understandable to the general public, for example in the form of annual reports. In this context the NGO's might play a role.

7. The recent mass mortality amongst the Wadden Sea harbour seals has shown wide gaps in our knowledge of seal population dynamics, this prevents the construction of effective management plans.

Though the Wadden Sea must be considered an ecological entity, it has never been possible to carry out a coordinated complete study of its seal population. In view of these facts it is recommended that an international cooperative project on the Wadden Sea harbour seal population which would be an appropriate reaction to the recent events and a first step towards sound management plans.

The project should be carried out by closely cooperating groups in the three Wadden Sea States.

The project should be started as early as possible and it should be continued for at least five years.

The project should result in the construction of a descriptive population model as a base for a management plan to ensure the restoration of the harbour seal population in the Wadden Sea.

8. Based on the results of the symposium, the symposium came to the conclusion that worldwide climatic changes and the resulting sea level rise, combined with progressive 
coastal defense, are a major threat to the Wadden Sea and need utmost attention. On a local scale the same is still true for the eutrophication problem.

9. The symposium should be developed in the direction of an open scientific symposium. This means:

- open access for all interested persons;

- symposium fees to cover at least a part of the expenses;

- quality control of proposed papers by a symposium committee;

- workshops within the symposium. 